\title{
Synthesis, electrical and magnetic properties of polymer coated magnetic nanoparticles for application in MEMS/NEMS
}

\author{
Muhammad Arshad Javid ${ }^{1, *}$, Muhammad SajJad ${ }^{1}$, SAEEd Ahmad $^{2}$, \\ Muhammad Azhar Shahid Khan ${ }^{2}$, Khalid NadeEm ${ }^{3}$, Niama Amin ${ }^{4}$, Zahid Mehmood \\ ${ }^{1}$ Department of Basic Sciences (Physics), University of Engineering and Technology, Taxila, 47050, Pakistan \\ ${ }^{2}$ Department of Physics, The Islamia University of Bahawalpur, 63100, Pakistan \\ ${ }^{3}$ Department of Physics, University of Gujrat, Gujrat, 50700, Pakistan \\ ${ }^{4}$ Department of Physics, CIIT, COMSAT, Lahore, 54750, Pakistan \\ ${ }^{5}$ Department of Software Engineering, University of Engineering and Technology, Taxila, 47050, Pakistan
}

\begin{abstract}
In this research work, polymer coated magnetic nanoparticles were prepared by co-precipitation method. The samples were characterized by XRD, SEM, EDS, VSM and two probe DC conductivity measurements. XRD pattern indicated the existence of a sole cubic phase of $\mathrm{Fe}_{3} \mathrm{O}_{4}$ with Miller indices (2 20 ), (3 11 1), (5 11 1), (4 4 0). An average size of magnetic nanoparticles was about $22.9 \mathrm{~nm}$ and it was reduced to $21.3 \mathrm{~nm}$ and $19.4 \mathrm{~nm}$ after $1 \mathrm{wt}$ \%. and $2 \mathrm{wt}$. \% coating of PEG-6000, respectively. The morphology and size of the samples were investigated by scanning electron microscope (SEM). EDX spectra confirmed the coating of PEG on magnetic nanoparticles. Magnetic properties were examined by vibrating sample magnetometer (VSM). Saturation magnetization $\left(\mathrm{M}_{s}\right)$ decreased as the concentration of PEG increased in the magnetic material. Electrical properties of uncoated and polymer coated $\mathrm{Fe}_{3} \mathrm{O}_{4}$ nanoparticles were studied by two-probe conductivity meter. This study concluded that the thermal flow of charge in polymer coated magnetic nanoparticles can be evaluated at micro and nano level.
\end{abstract}

Keywords: magnetic nanoparticles; polyethylene glycol; XRD; SEM; VSM

\section{Introduction}

$\mathrm{Fe}_{3} \mathrm{O}_{4}$ nanoparticles are widely used in various biomedical applications such as drug delivery systems, cell separation, cancer hyperthermia treatment, magnetic resonance imaging (MRI) contrast agents, tissue engineering and sensors [1-6]. Microelectromechanical systems (MEMS) are attractive for biologists due to their design and ability to control devices at micrometer scale [7, 8]. Microelectronic devices are becoming more and more popular as they have a potential for application in polymer-based MEMS and actuators in the biomedical field [9]. Polymer based magnetic nanoparticles are used in many electronic devices for formation of p-n junctions, design of conductive

*E-mail: arshadrahictn@gmail.com paths and to alter the material properties by thermal migration of charge [10-16].

Magnetite $\left(\mathrm{Fe}_{3} \mathrm{O}_{4}\right)$ has gained a great attention because it is environmentally harmless, economically and chemically stable [17-19]. Magnetite exhibits various electrical characteristics depending on its temperature. There are three phases of temperature in which magnetite behaves differently in terms of conductivity: one is the Verwey transition temperature ( $0 \mathrm{~K}$ to $119 \mathrm{~K})$, the second one, Curie temperature $T_{c}(120 \mathrm{~K}$ to $840 \mathrm{~K})$ and the third phase is above $840 \mathrm{~K}$. In Curie temperature phase, magnetite shows semiconductor characteristics. This phase transition property of magnetite makes it a possible choice for semiconductor devices as well as MEMS and NEMS [11].

Polyethylene glycol (PEG) has very low electrical conductivity but it plays a potential role in mixing with magnetic material to make the materials 
more stable [20]. In previous work, poly anthranilic acid (PANA)/magnetite and polystyrene/magnetite nanocomposite were studied in order to assess the electrical properties of the polymer based nanocomposites [21, 22].

In this work, PEG-6000 (polymer) coated magnetic nanoparticles have been synthesized by coprecipitation method and temperature based conductivity measurements were used to study the electrical properties of PEG coated magnetic nanoparticles.

\section{Materials and methods}

\subsection{Synthesis of polymer coated magnetic nanoparticles}

Ferrous chloride tetrahydrate $\left(\mathrm{FeCl}_{2} \cdot 4 \mathrm{H}_{2} \mathrm{O}\right.$, $98 \%$ chemical purity), ferric chloride hexahydrate $\left(\mathrm{FeCl}_{3} \cdot 6 \mathrm{H}_{2} \mathrm{O}, 98 \%\right.$ chemical purity), ammonium hydroxide, polyethylene glycol (PEG-6000) and deionized water have been used in this study. The magnetic nanoparticles were prepared using coprecipitation method. Ferric chloride hexahydrate and ferrous chloride tetrahydrate were mixed in 2:1 ratio. The solution was stirred continuously for 30 minutes at the $500 \mathrm{rpm}$ (rotation per minute). The solution of $\mathrm{NH}_{4} \mathrm{OH}$ was added by introducing small droplets with a pipette and $\mathrm{pH}$ was brought to 9 at room temperature. Finally, $\mathrm{Fe}_{3} \mathrm{O}_{4}$ nanoparticles were obtained in the form of iron oxide precipitates. The magnetic nanoparticles were dried at $80{ }^{\circ} \mathrm{C}$ for 24 hours. The chemical reaction of the product is expressed by equation $1[22,23]$ :

$$
\begin{aligned}
& \mathrm{FeCl}_{2}+2 \mathrm{FeCl}_{3}+8 \mathrm{NH}_{4} \mathrm{OH} \rightarrow \mathrm{Fe}_{3} \mathrm{O}_{4} \\
& +8 \mathrm{NH}_{4} \mathrm{Cl}+4 \mathrm{H}_{2} \mathrm{O}
\end{aligned}
$$

$\mathrm{Fe}_{3} \mathrm{O}_{4}$ nanoparticles were taken to make a solution of $100 \mathrm{ml}$ using deionized water. PEG (1 wt.\% and $2 \mathrm{wt} . \%$ ) was added into $100 \mathrm{ml}$ of water in two different beakers. Both the solutions were mixed on a magnetic stirrer plate for 3 hours at $400 \mathrm{rpm}$ at $60{ }^{\circ} \mathrm{C}$ and oleic acid $(20 \mathrm{ml})$ was added into each solution. Later on, each solution of PEG (1 wt.\% and 2 wt. \%) was sonicated for 30 minutes. The solutions of PEG coated $\mathrm{Fe}_{3} \mathrm{O}_{4}$ nanoparticles were centrifuged twice and washed with deionized water to remove the impurities from the product. Polymer coated magnetic nanoparticles were dried in a vacuum oven at $80^{\circ} \mathrm{C}$ for 24 hours.

\section{Results and discussion}

\subsection{XRD analysis}

XRD diffractometer (Model: PW 3710 operated at $45 \mathrm{kV}$ and $40 \mathrm{~mA}$ with $\mathrm{CuK} \alpha$ radiation) was used to identify the phases of magnetite and polymer coated magnetic nanoparticles. Four main peaks at $30.29^{\circ}, 35.68^{\circ}, 57.37^{\circ}, 63.00^{\circ}$ were found with reflections (2 200$),\left(\begin{array}{lll}3 & 1 & 1\end{array}\right),\left(\begin{array}{lll}5 & 1 & 1\end{array}\right)$, (4 40 ) as shown in Fig. 1. These Miller indices are matched with a standard JCPDS Card No. 01-0716338 [29]. XRD patterns indicate a cubic structure of the magnetic nanoparticles with an average grain size of $22.9 \mathrm{~nm}$. It is seen that the peaks intensity reduced after PEG coating on magnetic nanoparticles and the peak ( $\left.\begin{array}{lll}5 & 1 & 1\end{array}\right)$ disappeared at 2 wt.\% concentration of polymer. Actually, magnetite has been suppressed owing to the PEG coating due to its amorphous nature [24]. The grain size of magnetic nanoparticles was reduced from $22.9 \mathrm{~nm}$ to $21.3 \mathrm{~nm}$ and $19.4 \mathrm{~nm}$ due to PEG 1 wt. $\%$ and 2 wt. \% coating, respectively. The XRD results confirm that PEG-6000 have played a decisive role in controlling the size of magnetic nanoparticles [25]. The grain size of the samples was calculated from Scherrer's formula as shown in equation 2 :

$$
\tau=\frac{K \lambda}{\beta \cos \theta}
$$

where $\mathrm{k}=0.9$ and $\lambda=1.54 \AA$.

\subsection{SEM studies}

The morphology of magnetite and PEG coated magnetite was studied by using VEGA3 TESCAN SEM at $20 \mathrm{kV}$. The samples for SEM analysis were taken in a powder form. SEM images of pure magnetite are shown in Fig. 2a and PEG (1 wt. \% and 2 wt. \%) coated magnetic nanoparticles are shown in Fig. 2b, Fig. 2c, respectively. SEM images of $\mathrm{Fe}_{3} \mathrm{O}_{4}$ show that the surface is partially smooth and negligible agglomeration of nanoparticles is found due to high surface energy as well as due to 
Table 1. Calculation of grain size of the magnetite.

\begin{tabular}{|c|c|c|c|c|c|c|}
\hline $\begin{array}{l}\text { Peak } \\
\text { No. }\end{array}$ & Plane & $\begin{array}{l}\text { X-ray } \\
\text { wavelength } \\
(\lambda)[\AA]\end{array}$ & $\begin{array}{l}\text { FWHM (B) } \\
{[\mathrm{rad}]}\end{array}$ & Average angle $\left[\theta_{B}\right]$ & $\cos \theta_{\mathrm{B}}$ & $\begin{array}{l}\text { Grain } \\
\text { size }(\mathrm{t}) \\
{[\mathrm{nm}]}\end{array}$ \\
\hline 1 & $\left(\begin{array}{lll}2 & 2 & 0\end{array}\right)$ & 1.54 & $7.16 \times 10^{-3}$ & 15.008 & 0.965 & 20.0 \\
\hline 2 & $\left(\begin{array}{lll}3 & 1 & 1\end{array}\right)$ & 1.54 & $5.42 \times 10^{-3}$ & 17.704 & 0.952 & 26.9 \\
\hline 3 & $\left(\begin{array}{lll}5 & 1 & 1\end{array}\right)$ & 1.54 & $7.17 \times 10^{-3}$ & 28.580 & 0.878 & 22.0 \\
\hline 4 & $(440)$ & 1.54 & $7.15 \times 10^{-3}$ & 31.403 & 0.853 & 22.7 \\
\hline
\end{tabular}

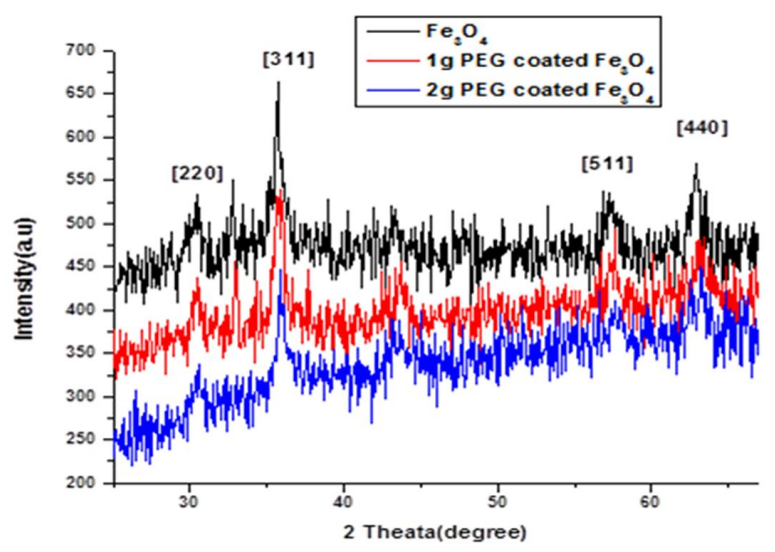

Fig. 1. X-ray diffraction patterns of $\mathrm{Fe}_{3} \mathrm{O}_{4}$ and polymer coated $\mathrm{Fe}_{3} \mathrm{O}_{4}$.

the magnetic interaction among the nanoparticles. SEM images confirm the cubic structure of $\mathrm{Fe}_{3} \mathrm{O}_{4}$ and regular arrangement of the particles [24]. Similarly, polymer coated magnetic nanoparticles also show negligible agglomeration due to van der Waal forces among the nanoparticles [25].

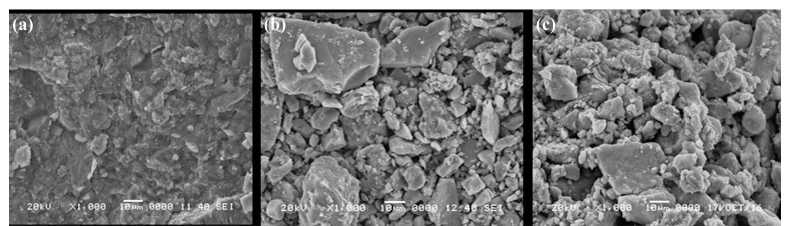

Fig. 2. SEM images of $\mathrm{Fe}_{3} \mathrm{O}_{4}$ : (a) magnetite, (b) polymer coated $\mathrm{Fe}_{3} \mathrm{O}_{4}: 1$ wt.\% PEG, (c) 2 wt.\% PEG.

\subsection{EDX spectra analysis}

The composition of the magnetic nanoparticles was studied by EDX (energy dispersive spectroscopy) as illustrated in Fig. 3a for $\mathrm{Fe}_{3} \mathrm{O}_{4}$ and PEG (1 wt.\% and 2 wt.\%) coated magnetic nanoparticles as shown in Fig. $3 \mathrm{~b}$ and $3 \mathrm{c}$, respectively. The EDX study confirms the adsorption of PEG on the surface of the magnetite nanoparticles. Fig. 3a shows the peaks of $\mathrm{Fe}, \mathrm{O}$ and $\mathrm{Cl}$ in the synthesized samples of the magnetic nanoparticles. Fig. $3 \mathrm{~b}$ shows the peaks of $\mathrm{Fe}, \mathrm{O}$ and $\mathrm{C}$ in the sample of 1 wt.\% PEG coated magnetic nanoparticles. In the sample of 2 wt.\% PEG coated magnetic nanoparticles, the peaks of $\mathrm{Fe}$, $\mathrm{Cl}, \mathrm{O}$ and $\mathrm{C}$ can be seen (Fig. 3c). Here, the existence of carbon element confirms the coating of polymer on the surface of magnetic nanoparticles. The average atomic percentage of $\mathrm{Fe}$ and $\mathrm{C}$ and $\mathrm{O}$ peaks have been obtained as the ratio of $\mathrm{O} / \mathrm{Fe} / \mathrm{C}=46.97 / 34.02 / 16.9[26,27]$.

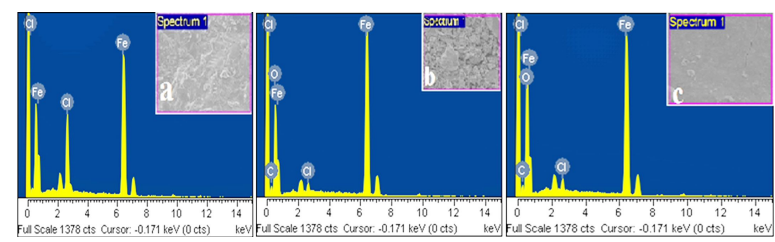

Fig. 3. EDX spectra of magnetic nanoparticles (a) pure $\mathrm{Fe}_{3} \mathrm{O}_{4}$, (b) (1 wt.\% PEG) polymer coated $\mathrm{Fe}_{3} \mathrm{O}_{4}$, (c) (2 wt.\% $\mathrm{PEG}$ ) polymer coated $\mathrm{Fe}_{3} \mathrm{O}_{4}$.

\subsection{VSM analysis}

Magnetic properties of the samples were studied by vibrating sample magnetometer (VSM-100), Dexing Magnet Tech Co., China. The magnetization curves were measured at room temperature using 1.0 Tesla unit. Fig. 4 shows the saturation magnetization of magnetic nanoparticles and 
PEG-6000 coated magnetic nanoparticles [28, 29]. The saturation magnetization $\left(\mathrm{M}_{\mathrm{S}}\right)$ of magnetite $\left(\mathrm{Fe}_{3} \mathrm{O}_{4}\right)$ was $52.02 \mathrm{emu} / \mathrm{g}$. The saturation magnetization $\left(\mathrm{M}_{\mathrm{S}}\right)$ of PEG (1 wt.\%, 2 wt.\%) coated magnetic nanoparticles was assessed as $28.71 \mathrm{emu} / \mathrm{g}$ and $19.21 \mathrm{emu} / \mathrm{g}$, respectively [30]. The difference in saturation magnetization of $\mathrm{Fe}_{3} \mathrm{O}_{4}$ nanoparticles and polymer coated $\mathrm{Fe}_{3} \mathrm{O}_{4}$ was due to the difference in particle size. PEG coated magnetic $\mathrm{Fe}_{3} \mathrm{O}_{4}$ nanoparticles showed reduced saturation magnetization due to smaller size of magnetic nanoparticles as compared to pure $\mathrm{Fe}_{3} \mathrm{O}_{4}$ [31]. The saturation magnetization measurements results were very close to the results reported by Anbarasu et al. et al. [32]. Actually, the saturation magnetization of PEG coated magnetic nanoparticles was reduced due to the decrease in the crystallite size of magnetic nanoparticles and diamagnetic coating shell of polymer on the surface of magnetic nanoparticles [29].

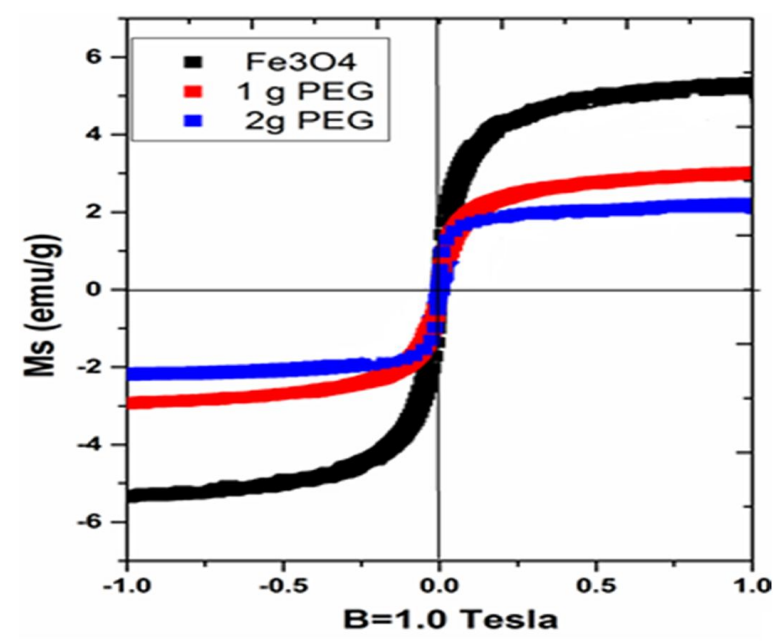

Fig. 4. Magnetization curves of $\mathrm{Fe}_{3} \mathrm{O}_{4}$ and polymer coated $\mathrm{Fe}_{3} \mathrm{O}_{4}$.

\subsection{Electrical analysis}

Several studies have been devoted to the study on conductivity of polymer coated $\mathrm{Fe}_{3} \mathrm{O}_{4}$ nanoparticles. The conductivity of polymer based magnetic nanoparticles is important for fabrication of microdevices and microfluidic chips for biomedical application. Similarly, polymer-based magnetic materials have a wide range application in electromagnetic MEMS actuators [33]. Lisa Vella et al. presented the electrical conductivity of iron oxides nanoparticles with different concentrations of magnetite at different voltages to sense the electromagnetic effects in thin films, bio MEMS and magnetic actuators [34].

In this study, the electrical properties of magnetite $\left(\mathrm{Fe}_{3} \mathrm{O}_{4}\right)$ and polymer coated $\mathrm{Fe}_{3} \mathrm{O}_{4}$ have been investigated by two-probe conductivity meter (SES Model 1154, India). Previous studies demonstrated semiconductor characteristics of $\mathrm{Fe}_{3} \mathrm{O}_{4}$. $\mathrm{Fe}_{3} \mathrm{O}_{4}$ has a very small band gap of $0.1 \mathrm{eV}$ and the lowest resistivity compared to any other oxide. It has high conductivity of $10^{2}-10^{3} \Omega^{-1} \mathrm{~cm}^{-1}$. $\mathrm{Fe}^{+2}$ and $\mathrm{Fe}^{+3}$ ions are close to each other in octahedral sites and the holes can migrate easily from $\mathrm{Fe}^{+2}$ and $\mathrm{Fe}^{+3}$ ions and this accounts for good conductivity of iron oxides [35]. In this study, temperature dependent electrical properties of the polymer coated $\mathrm{Fe}_{3} \mathrm{O}_{4}$ were studied in order to compare them with the elements of G-III/G- IV which are commonly used in the fabrication of bio MEMS/NEMS, MEMS switches, magnetic actuators and magnetic thin films. The electrical conductivity of any material represents the material ability to conduct electric current and is the reciprocal of electrical resistivity. The conductivity $\sigma$ of $\mathrm{Fe}_{3} \mathrm{O}_{4}$ nanoparticles and PEG coated $\mathrm{Fe}_{3} \mathrm{O}_{4}$ is shown in Fig. 5a and Fig. 5b. It is seen that the conductivity of the nanoparticles increases at higher temperatures which is an intrinsic property of semiconductors [36]. The conductivity of magnetite and polymer coated magnetite at different temperatures are collected in Table 2 [37]. Equation 3 and equation 4 have been used to calculate the conductivity of the samples:

$$
\rho=\frac{R A}{L}
$$

$$
\sigma=\frac{1}{\rho}
$$

Here, $A$ is the surface area of the base of the cylindrical pellet and $\mathrm{L}$ is the length of the pellet $(\mathrm{A}=$ $139.48 \mathrm{~mm}^{2}$ and $\mathrm{L}=5.15 \mathrm{~mm}$ ). 
Table 2. Conductivity and current values of the samples at different temperatures.

\begin{tabular}{ccccccc}
\hline Temperature & $\mathrm{Fe}_{3} \mathrm{O}_{4}$ & Current $(\mathrm{I})$ & $\begin{array}{l}\text { PEG } \\
(1 \mathrm{wt} \%)\end{array}$ & Current $(\mathrm{I})$ & $\begin{array}{l}\text { PEG } \\
(2 \mathrm{wt} . \%)\end{array}$ & Current (I) \\
\hline $\mathrm{C}$ & $\begin{array}{c}(\sigma) \\
\mathrm{mS} / \mathrm{m}\end{array}$ & $\mu \mathrm{A}$ & $(\sigma) \mathrm{mS} / \mathrm{m}$ & $\mu \mathrm{A}$ & $(\sigma) \mathrm{mS} / \mathrm{m}$ & $\mu \mathrm{A}$ \\
\hline \hline 90 & 0.01034 & 1.4 & 0.0004 & 0.20 & 0.00131 & 0.1 \\
100 & 0.01551 & 2.1 & 0.00183 & 0.3 & 0.00197 & 0.4 \\
110 & 0.02363 & 3.2 & 0.00274 & 0.6 & 0.00393 & 0.6 \\
120 & 0.03397 & 4.6 & 0.00457 & 0.8 & 0.00524 & 1 \\
130 & 0.04947 & 6.7 & 0.00732 & 1.2 & 0.00786 & 1.6 \\
140 & 0.07089 & 9.6 & 0.01235 & 1.8 & 0.0118 & 2.7 \\
150 & 0.1019 & 13.8 & 0.01875 & 2.6 & 0.01704 & 4.1 \\
160 & 0.14621 & 19.8 & 0.02973 & 3.8 & 0.0249 & 6.5 \\
170 & 0.20676 & 28 & 0.04299 & 5 & 0.03276 & 9.4 \\
180 & 0.31383 & 42.5 & 0.06128 & 6.3 & 0.04128 & 13.4 \\
190 & 0.41646 & 56.4 & 0.08781 & 7.9 & 0.05177 & 19.2 \\
200 & 0.56859 & 77 & 0.11474 & 8.7 & 0.05701 & 25.1 \\
\hline
\end{tabular}

The conductivity of the nanoparticles has not improved after coating with $1 \mathrm{wt} . \%$ and $2 \mathrm{wt} . \%$ of PEG at all studied temperatures as shown in Fig. 5a and Fig. 5b. In this study we have also determined the thermal flow of charge in magnetic and nonmagnetic materials to use in many devices such as MEMS, NEMS, sensors, solar cells, magnetic actuators and thin magnetic films [36, 38].
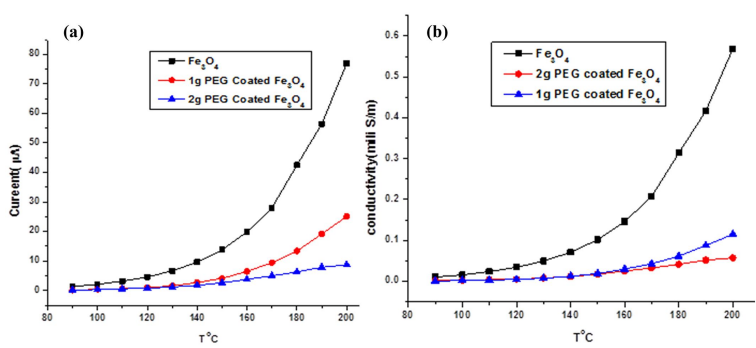

Fig. 5. (a) Variation of current (I) versus $\mathrm{T}\left({ }^{\circ} \mathrm{C}\right)$, (b) Variation of $(\sigma)$ versus $\mathrm{T}\left({ }^{\circ} \mathrm{C}\right)$.

\section{Conclusions}

In this study, PEG coated magnetic nanoparticles were synthesized by co-precipitation method. The XRD patterns showed that crystallite size of $\mathrm{Fe}_{3} \mathrm{O}_{4}$ decreased from $22.9 \mathrm{~nm}$ to $21.3 \mathrm{~nm}$ and
$19.4 \mathrm{~nm}$ after PEG coating, respectively. SEM images of $\mathrm{Fe}_{3} \mathrm{O}_{4}$ revealed that their surface is relatively smooth and shows no agglomeration of magnetic nanoparticles. PEG-600 coating on the surface of $\mathrm{Fe}_{3} \mathrm{O}_{4}$ further reduced the agglomeration due to van der Waals forces. EDX spectra confirmed the presence of polymer on the $\mathrm{Fe}_{3} \mathrm{O}_{4}$ surface. The difference in saturation magnetization of uncoated magnetite and polymer coated magnetite was due to the difference in particle size. The electrical characteristics of magnetic nanoparticles and polymer coated magnetic nanoparticles depend on temperature and the flow of charge in the samples is enhanced at higher temperature. It is concluded that PEG coating on the surface of magnetic nanoparticles may control the flow of charge in the samples even at higher temperature. Polymer coated magnetic nanoparticles showed the temperature dependent conductivity that is an intrinsic property of semiconductor materials. This study also demonstrated the thermal flow of charge in magnetic and nonmagnetic material at micro and nano level.

\section{References}

[1] Oliveira D., Barud S., Salvi D., Perotti G., Riberio S., Indian Crop. Prod., 69, (2015), 415.

[2] Xu H., Cheng L., Wang C., Ma X., Li Y., LiU Z., Biomaterials, 32: (2011), 9364. 
[3] Chai C.C., Lee Z.H., Toh P.Y., Chieh C.J, Ahmad A.L., LIM J.K., Chem. Eng. J., 281, (2015), 523.

[4] Hauser A.K., Wydra R.J., Stocke A., AnderSON W., HiLt Z., J. Cont. Rel., 219, (2015), 76.

[5] Leng J., Li J., Ren J., Deng L., Lin C., Mater. Lett., 152, (2015), 185.

[6] Heid A., Bahrololoom M., Vashaee D., Tayebi I., Ceramic. International., 41, (2015), 3094.

[7] Omidi H.M., MahbоObeh A., FARIDeh P., Materials Science-Poland 35, (2017), 105-110.

[8] Sun X., Keating A., Parish G., Micropor. Mesopor. Mat., 218, (2015), 88.

[9] Thangawng A.L., Rodney S.R., Melody A.S., Biomedical Microdevices 9, (2007), 587-595.

[10] JAVID MA., SADAQAT N., RAFIQUE M., Materials Today: Proceedings. (2020).

[11] JaVid Ma., U.ZAFAR, H.FAYYAZ, M.IMRAN., Int. J. Mod. Phys. B, 32 (14), (2018), 13.

[12] Javid MA., FAYYAZ H., IMran M., Mater. Sci.Poland, 34, (2016), 741.

[13] Azeem N., Ma. JaVid, TahiR I., J. Semicond, 38. (2017), 7.

[14] Sabater AB., JefF R., J. Micromech. Microeng., 24, (2014), 065005.

[15] Narbutovskih M., Field L., Clifford G., Beck P., Sensor. Actuat. A-Phys., 70 , (1998), 128.

[16] KIM S., Roy S., Adv. Chronic. Kidney D, 20, (2013), 516.

[17] Attallah A., Girgis E., J. Magn. Magn. Mater., 399, (2016), 58.

[18] Manrique J., Machuca F., Marriga F., J. Magn. Magn. Mater., 401, (2016), 81.

[19] Li X., Liu G., Yan W., Chu P.K., Wu S., Yi C., XU Z., J. Magn. Magn. Mater., 324, (2012), 1410.

[20] Cantalapiedra A., Gismera M.J., Procopio JR., SEVILla M.T., Talanta, 139, (2015), 111.

[21] Cornell R.M., Schwertmann U., The iron oxides. VCH Press, Weinheim, Germany, (1996).
[22] Arshad J., Saddique A., Zahid M., Mater. SciPoland, 25 (2019), 359.

[23] JAVID M.A., Materials Today: Proceedings (2020).

[24] Harsha N., Swathi K., NeEroli K.R., SATyajit S., RSC Adv., 38, (2015), 30354.

[25] Takenaka K., Ozawa A., Shibayama T., Urano C., Appl. Phys. Letters; 9 (2011), 022103.

[26] Katikaneani P., Ajay K V., Narender RT., Ramu B., SRIVANi K., J. Nanosci., (2016).

[27] Shanmuga Si., Mayank S., Shampa S., Transl. Biomed., 6,3: (2015).

[28] Franco A., Thiago AL., Emília Li., Eloisa N., Appl. Phys. A, 94 (1) (2009), 131.

[29] Markhulia J., Mikelashvili V., Kekutia L., $J$. Pharm. Appl. Chem., 2, (2016), 33.

[30] Khalkhali M., Rostamizadeh K., Sadighian S., J. Pharm. Sci., 23 (2015), 45.

[31] Mahdavi M., Ahmad B., Haron J., Rahman A., J., Molecules, 18 (2013), 7533.

[32] Anbarasu M., Anandan E., Chinnasamy V., Gopinath K., Spectrochim. Acta A, 135 (2015), 536.

[33] Yunas J., Polymers, 5 (2020), 1184.

[34] Vella L., EMERSON D., ASEG Extended Abstracts, 1 (2012), 1.

[35] Schwertmann U., Rochelle MC., Iron oxides in the laboratory: preparation and characterization. John Wiley \& Sons, 2008.

[36] Eslamian M., Morteza M., Ziad S., Fluid Dynamics and Material Processing, 2012.

[37] Weidenfeller E., Höfer M., Frank S., Composites Part A: Appl. Sci. Manuf, 33, (2002), 1041.

[38] Cimalla V., Joerg P., Oliver A., J. Physics D: Appl. Phys, 40, 20 (2007), 6386.

Received 2018-04-14 Accepted 2020-12-18 